\title{
Liver-dominant Breast Cancer Metastasis: A Comparative Outcomes Study of Chemoembolization Versus Radioembolization
}

\author{
JODIE CHANG ${ }^{1}$, RESMI CHARALEL ${ }^{2}$, CHRISTOPHER NODA $^{1}$, RAJA RAMASWAMY $^{1}$ \\ SEUNG KWON KIM ${ }^{1,3}$, MICHAEL DARCY ${ }^{1,3}$, GRETCHEN FOLTZ ${ }^{1}$ and OLAGUOKE AKINWANDE ${ }^{1,3}$ \\ ${ }^{1}$ Division of Interventional Radiology, Mallinckrodt Institute of Radiology, \\ Washington University School of Medicine in St. Louis, St. Louis, MO, U.S.A.; \\ ${ }^{2}$ Division of Interventional Radiology, Weill Cornell Medicine/New York Presbyterian Hospital, New York, NY, U.S.A.; \\ ${ }^{3}$ Siteman Cancer Center at Washington University in St. Louis, St. Louis, MO, U.S.A.
}

\begin{abstract}
Aim: To compare toxicity, response, and survival outcomes of patients with hepatic metastases from breast cancer who underwent transarterial chemoembolization (TACE) or radioembolization (TARE). Materials and Methods: A retrospective review was carried out of all patients who underwent TACE or TARE for liver-dominant breast cancer metastases between January 2006 and March 2016 at an academic medical center in the United States. Results: Seventeen patients in the TACE group and 30 patients in the TARE group received 32 TACE and 49 TARE treatments, respectively. Median follow-up was 9 months. Both groups had similar background variables. More allgrade adverse events were seen in the TACE group $(71 \% \mathrm{vs}$. $44 \% ; p=0.02)$. Median overall survival in the TACE group was 4.6 months compared to 12.9 months in the TARE group $(p=0.2349)$. Treatment type was not an independent prognostic factor. Conclusion: TARE is better tolerated than TACE for the treatment of liver-dominant breast cancer metastasis. There was a trend towards improved survival with TARE; however, it did not approach statistical significance. Larger studies are needed to validate these findings.
\end{abstract}

Breast cancer is the most common malignancy in women, and the second leading cause of cancer-related deaths for women in the United States. It is estimated that one out of eight women will be diagnosed with breast cancer during

Correspondence to: Olaguoke Akinwande, MD, Assistant Professor of Radiology and Surgery, Division of Interventional Radiology, Department of Radiology, Washington University School of Medicine in St. Louis, St. Louis, MO 63110, U.S.A. Tel: +1 3143622978, e-mail: oakinwa@wustl.edu

Key Words: Chemoembolization, radioembolization, breast cancer, locoregional therapy, metastasis. their lifetime (1). The 5-year survival rate for women with localized disease at diagnosis is $98 \%$; however, this rate drops to $24 \%$ for those who present with distant disease (2). While it is uncommon to have metastatic disease at initial presentation, $30 \%$ of women will eventually develop recurrent advanced or metastatic disease, most commonly involving the brain, lungs, liver, and bone $(3,4)$.

Liver metastases eventually develop in approximately $20 \%$ of patients and confer a poor prognosis (5). For patients with liver-only or liver-dominant metastases, hepatectomy has been shown to improve 5-year survival (6). Unfortunately, most patients are not surgical candidates and have chemoresistant, multi-organ disease (6). For these patients, transarterial chemoembolization (TACE) with doxorubicin and transarterial radioembolization (TARE) with yttrium-90 have both been shown to be safe and effective (7-11).

The purpose of this study was to compare toxicity, treatment response, and survival outcomes of patients with liver-dominant metastases from breast cancer who underwent TACE or TARE.

\section{Materials and Methods}

Patient selection. A retrospective review was performed to identify all patients who underwent TACE or TARE for the treatment of liver-dominant breast cancer metastases $(>50 \%$ overall disease burden confined to the liver) at a single academic quaternary referral center in the United States during a 10-year period from January 2006 to March 2016. Seventeen patients comprised the TACE group and received a total of 35 treatments (one conventional TACE with doxorubicin, 31 with doxorubicin-eluting beads, and three cross-over with SIR-Spheres (Sirtex)). Thirty patients formed the TARE group and received a total of 52 treatments (three TheraSpheres (BTG Interventional Medicine), 46 SIR-Spheres, and three cross-over with doxorubicin-eluting beads). TheraSpheres are glass microspheres ranging in size from 20-30 $\mu \mathrm{m}$ with a shelf-life of 12 days, mild embolic effect, and ability to deliver between 3-20 $\mathrm{GBq}$ of activity. SIR-Spheres are resin microspheres ranging in size 
from 20-60 $\mu \mathrm{m}$ with a shelf-life of 1 day, moderate embolic effect, and ability to deliver up to $3 \mathrm{GBq}$ of activity (12). No patient received prior locoregional treatment. All patients underwent standard pretreatment evaluation including liver imaging [computed tomography $(\mathrm{CT})$ or magnetic resonance imaging (MRI)] prior to embolization. This study was approved by an Institutional Review Board (IRB ID\# 201608028). The decision of which treatment modality to use was decided by a multidisciplinary team. Inclusion criteria for treatment with transarterial therapy at our Institution included age $>18$ years, histological proof of metastatic disease to the liver, Eastern Cooperative Oncology Group performance status score $\leq 2$, life expectancy $>3$ months, and ability to give informed consent. Exclusion criteria included pregnancy, contraindications to angiography, severe liver dysfunction, severe cardiac comorbidities, and $>75 \%$ hepatic parenchymal involvement. Only patients with liver-dominant disease were considered for treatment. Those patients that had both chemoembolization and radioembolization were grouped according to their index treatment $(n=3)$.

Chemoembolization technique. Mesenteric angiography was performed to evaluate hepatic arterial anatomy, tumor vascularity, portal vein patency, and arteriovenous shunting. Patients received one to two (for bilateral disease) treatments depending on the extent of liver involvement and initial response to treatment. Treatments were spaced at 3- to 4-week intervals depending on patient toxicity. There was one treatment with conventional TACE. The remainder of the treatments involved 100-300 $\mu \mathrm{m}$ drug-eluting beads (median doxorubicin dose delivered=50 mg; range $=25-100 \mathrm{mg}$ ). Lobar versus segmental treatment and placement of the microcatheter for drug delivery was dependent on the extent of liver involvement and location of metastases.

Radioembolization technique. Patients underwent a mapping study approximately 2-3 weeks prior to their first treatment. Mesenteric angiography was performed to evaluate hepatic arterial anatomy and optimal microcatheter placement. ${ }^{99 \mathrm{~m} T e c h n e t i u m-m a c r o a g g r e g a t e d}$ albumin was delivered via the hepatic artery to evaluate pulmonary shunting and unwanted gastrointestinal deposition. Planar scintigraphy was used to calculate shunt fractions. Coil embolization of vessels was performed when indicated. SIR-Spheres and TheraSphere delivery systems were utilized in this study and dose calculations were performed according to the respective manufacturer's published guidelines.

Follow-up and outcome measures. Follow-up was dependent on our Institutional protocol. Patients were assessed for treatment-related adverse events within 1-month post treatment according to the standards and terminology outlined in the Cancer Therapy Evaluation Program's Common Terminology Criteria for Adverse Events version 3.0 (13). They underwent post-treatment follow-up imaging (CT or MRI), 1 month (for TACE) or 3 months (for TARE) after completion of treatment. Tumor response to treatment was measured according to the modified Response Evaluation Criteria in Solid Tumors (mRECIST) criteria (14). The overall response rate (ORR) was defined as complete and partial responders. Overall survival (OS) was defined as the time from the start of treatment to death from any cause.

Statistical analysis. An intent-to-treat analysis was performed. Student's $t$-test was used for continuous data. The Fisher's exact test (two-tailed) was used for categorical data comparison. KaplanMeier and multivariate Cox regression were performed to assess survival. $p$-Values less than 0.05 were considered statistically
Table I. Baseline patient characteristics.

\begin{tabular}{|c|c|c|c|}
\hline Characteristic & TACE & TARE & $p$-Value \\
\hline Number of patients & 17 & 30 & \\
\hline \multicolumn{4}{|l|}{ Age, years } \\
\hline Median (range) & $48(34-67)$ & $55(31-82)$ & 0.112 \\
\hline Female gender, $\mathrm{n}$ & 17 & 30 & \\
\hline Hepatitis, $n$ & 0 & 1 & $>0.9999$ \\
\hline \multicolumn{4}{|l|}{ ECOG score (diagnosis), $n$} \\
\hline $0-2$ & 17 & 30 & $>0.9999$ \\
\hline$>2$ & 0 & 0 & \\
\hline Distinct number, $\mathrm{n}$ & 7 & 15 & \\
\hline Numerous $(>10), \mathrm{n}$ & 10 & 15 & \\
\hline \multicolumn{4}{|l|}{ Tumor location, $\mathrm{n}$} \\
\hline Left & 11 & 16 & 0.487 \\
\hline Right & 6 & 12 & \\
\hline Bilateral & 0 & 2 & \\
\hline \multicolumn{4}{|l|}{ Breast cancer histology, $\mathrm{n}$} \\
\hline Ductal & 14 & 17 & 0.08 \\
\hline Lobular & 0 & 2 & \\
\hline Mammary & 0 & 2 & \\
\hline Inflammatory & 1 & 0 & \\
\hline Unknown/not recorded & 1 & 9 & \\
\hline Synchronous disease, $\mathrm{n}$ & 2 & 4 & 0.877 \\
\hline Extrahepatic disease, $\mathrm{n}$ & 2 & 5 & 0.650 \\
\hline Prior chemotherapy, $\mathrm{n}$ & 17 & 30 & $>0.9999$ \\
\hline Concurrent chemotherapy, $\mathrm{n}$ & 4 & 3 & 0.2350 \\
\hline Prior liver surgery/RFA, $\mathrm{n}$ & 2 & 1 & 0.5473 \\
\hline Post liver surgery/RFA, n & 1 & 0 & 0.3617 \\
\hline Prior radiation therapy, $\mathrm{n}$ & 0 & 0 & $>0.9999$ \\
\hline \multicolumn{4}{|l|}{ Genetics/biomarkers, n } \\
\hline BRCA & 1 & 1 & 0.733 \\
\hline ER & 11 & 21 & \\
\hline PR & 11 & 20 & \\
\hline HER2-neu & 0 & 2 & \\
\hline \multicolumn{4}{|l|}{ Extrahepatic metastasis, $n$} \\
\hline Total & 15 & 20 & 0.1 \\
\hline Lymph node & 2 & 6 & \\
\hline Lung & 6 & 3 & \\
\hline Bone & 11 & 16 & \\
\hline
\end{tabular}

TACE: Transarterial chemoembolization, TARE: transarterial radioembolization, ECOG: Eastern Cooperative Oncology Group, RFA: radiofrequency ablation, BRCA: breast cancer susceptibility gene, ER: estrogen receptor, PR: progesterone receptor, HER2-neu: human epidermal growth factor receptor 2 .

significant. All statistics were calculated using JMP Software (JMP, SAS Institute Inc, Cary, NC, USA).

\section{Results}

Demographics and clinical characteristics. Using the aforementioned selection criteria, 47 female patients who received TACE or TARE for liver metastases from breast cancer were identified. Median follow-up was 9 months (range=1-109 months). Seventeen patients were treated with TACE, while 30 patients were treated with TARE. Of note, one patient received TACE then subsequently received TARE. 
Table II. Treatment factors.

\begin{tabular}{|c|c|c|}
\hline Characteristic & TACE & TARE \\
\hline Number of treatments & 35 & 52 \\
\hline Number of crossover treatments & 3 & 3 \\
\hline \multicolumn{3}{|l|}{ Type of treatment, $\mathrm{n}$} \\
\hline Conventional TACE & 1 & 0 \\
\hline Doxorubicin-eluting beads & 31 & $3^{*}$ \\
\hline${ }^{90} \mathrm{Y}$ TheraSpheres & 0 & 3 \\
\hline SIR-Spheres & $3 * *$ & 46 \\
\hline \multicolumn{3}{|l|}{ Level of branching, $n$} \\
\hline Whole liver & 0 & 0 \\
\hline Lobar & 30 & 48 \\
\hline Segmental & 5 & 4 \\
\hline \multicolumn{3}{|l|}{ Lobe treated, $\mathrm{n}$} \\
\hline Left & 12 & 16 \\
\hline Right & 5 & 12 \\
\hline Bilateral & 0 & 2 \\
\hline \multicolumn{3}{|l|}{ 90Y Activity delivered, Gbq } \\
\hline Median (range) & - & $0.8(0.18-3.53)$ \\
\hline \multicolumn{3}{|l|}{ Doxorubin dose delivered, $\mathrm{mg}$} \\
\hline Median (range) & $50(25-100)$ & - \\
\hline
\end{tabular}

TACE: Transarterial chemoembolization, TARE: transarterial

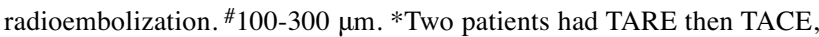
**one patient had TACE then TARE.

Likewise, two patients received TARE then subsequently received TACE. Crossover treatments were performed for patients whose disease progressed on the index treatment. Both groups had similar background variables including age, ECOG performance status, tumor extent, tumor location, breast cancer histology, genetic biomarkers, prior chemotherapy, concurrent chemotherapy, extrahepatic disease, extra-hepatic metastases and prior liver surgery. No patient received prior locoregional therapy (Table I).

Treatment factors and adverse events. There were 32 TACE treatments in 17 patients [one conventional TACE with doxorubicin (3\%), 31 doxorubicin drug-eluting beads $(97 \%)$ ]. There were 49 TARE treatments in 30 patients [three with TheraSpheres (6\%), 46 with SIR-Spheres (94\%)]. In the TACE group, there were three crossover treatments with SIR-Spheres, and in the TARE group, there were three crossover treatments with doxorubicin-loaded drug-eluting beads for patients who progressed on the index treatment modality. Median ytrrium-90 activity was $0.79 \mathrm{GBq}$ (range $=0.18-1.82 \mathrm{GBq})$. Both groups received predominantly lobar treatment (92\%) (Table II).

More all-grade adverse events were seen in the TACE group ( $71 \%$ versus $44 \% ; p=0.02)$. High-grade adverse events were seen in the TACE group, but not in the TARE group; however, this difference did not reach statistical significance (TACE 9\%, TARE 0\%; $p=0.06$ ). The most common all-grade side-effects were nausea, vomiting, and pain in both groups
Table III. Adverse events.

\begin{tabular}{lccc}
\hline Side-effects & $\begin{array}{c}\text { TACE }(\mathrm{n}=35) *, \\
\mathrm{n}(\%)\end{array}$ & $\begin{array}{c}\text { TARE }(\mathrm{n}=52) *, \\
\mathrm{n}(\%)\end{array}$ & $p$-Value \\
\hline All grade & $25(71 \%)$ & $23(44 \%)$ & 0.02 \\
Nausea and vomiting & $7(20 \%)$ & $15(29 \%)$ & \\
Pain & $15(43 \%)$ & $11(21 \%)$ & \\
Other & $6(17 \%)$ & $6(12 \%)$ & 0.06 \\
Grade $\geq 3$ & $3(9 \%)$ & 0 & 0.06 \\
\hline
\end{tabular}

TACE: Transarterial chemoembolization, TARE: transarterial radioembolization. *Number of treatments (includes 3 crossovers in the TACE group and 3 crossovers in the TARE group).

(Table III). Among the patients who had grade 3 or more adverse events, one had severe persistent left-sided abdominal pain following her treatment, likely a result of postembolization syndrome. She was admitted to the hospital for 2 days. Several months after treatment, another patient developed pain and transaminitis secondary to infarction of her liver from TACE and was hospitalized for 2 days. A third patient developed post-procedural leukocytosis following her treatment and was hospitalized for 4 days.

Treatment efficacy and survival. The overall modified RECIST response rate (complete response and partial response) for TACE at the first imaging follow-up was $24 \%$, compared to $40 \%$ in the TARE group $(p=0.3427)$. One patient who received TACE had a complete response. She received one TACE treatment for two liver lesions that had increased in size, measuring $30 \mathrm{~mm}$ and $8 \mathrm{~mm}$ prior to TACE. On follow-up imaging 1 month after her treatment, there was no residual enhancement of the lesions. Treatment response was unknown for two patients in the TACE group and one patient in the TARE group who were lost to followup after treatment (Table IV).

Median OS was significantly shorter in the TACE group with 4.6 months (95\% confidence interval=1.8 to 23.9 months) compared to 12.9 months ( $95 \%$ confidence interval $=5.3$ to 19.7 months $)$ in the TARE group $(p=0.2349)$.

Multivariate Cox regression analysis. Multivariate Cox regression analysis was used to evaluate the association between independent variables and survival. The variables included age, prior liver surgery, synchronous disease, presence of extrahepatic disease, treatment type (TACE or TARE), site of disease (left, right, bilateral), number of lesions, ECOG performance status, prior liver surgery, concurrent chemotherapy, tumor histology (ductal, non-ductal), and estrogen receptor (ER), progesterone receptor, and human epidermal growth factor receptor 2-neu receptor status.

Treatment type was not found to be an independent prognostic factor on multivariate analysis (Figure 1). 
Table IV. Image-based treatment response and progression at first follow-up.

\begin{tabular}{lcc}
\hline Response & TACE $(\mathrm{n}=17)$ & TARE $(\mathrm{n}=30)$ \\
\hline CR & 1 & 0 \\
PR & 3 & 12 \\
SD & 1 & 2 \\
PD & 10 & 15 \\
ORR* & 4 & 12 \\
Death from disease & 0 & 0 \\
Unknown status & 2 & 1 \\
\hline
\end{tabular}

TACE: Transarterial chemoembolization, TARE: transarterial radioembolization, $\mathrm{CR}$ : complete response, $\mathrm{PR}$ : partial response, $\mathrm{SD}$ : stable disease, PD: progressive disease, ORR: overall response rate, includes complete response and partial response. ${ }^{*} p=0.3427$.

Multivariate analysis revealed ER status and performance status to be independent prognostic factors (Table V).

\section{Discussion}

Over the past few decades novel chemotherapeutics and advancements in genetic testing and hormone therapy have led to improved outcomes in women with breast cancer, but up to $30 \%$ of women will eventually experience relapse and develop metastatic disease $(15,16)$. Liver metastases confer a poor prognosis, with ensuing liver dysfunction prompting the modification of ongoing chemotherapeutic regimens (1719). TARE has been demonstrated to be both safe and efficacious in patients with unresectable, chemoresistant disease (9-11). In our study, the median OS in the TARE group was 12.9 months (95\% confidence interval=5.3 to 19.7 months). This is similar to the OS of 13.6, 11.5, and 11.8 months reported by Saxena et al. (9), Haug et al. (20) and Cianni et al. (21). Other studies report shorter OS times of 6.6 and 8.8 months, but these are well within the confidence interval of our study (Table VI) $(8,10,11)$.

The median OS of the TACE group in our study was 4.6 months (95\% confidence interval $=1.8$ to 23.9 months). The literature supporting the use of TACE in this patient population is not as robust as that for TARE, but several studies do exist for comparison. For example, a small study performed by Giroux et al. demonstrated a mean survival time of 6 months from the first chemoembolization treatment (22). A more recent study by Lin et al. demonstrated a longer median OS of 17 months (7); however, their study utilized smaller 70-150 $\mu \mathrm{m}$ microspheres for drug delivery (Table VII). The authors postulated that this may enable for deeper deposition of the drug within the tumor vasculature.

Drug-eluting beads have been used as part of TACE for patients with hepatocellular carcinoma (HCC), and studies have looked at the efficacy of chemoembolization versus
Table V. Logistic regression for background variables affecting treatment outcomes.

\begin{tabular}{lccc}
\hline Parameter & $\begin{array}{c}\text { Hazard } \\
\text { ratio }\end{array}$ & $\begin{array}{c}95 \% \text { Confidence } \\
\text { interval }\end{array}$ & $p$-Value \\
\hline $\begin{array}{l}\text { Prior liver surgery } \\
\text { No }\end{array}$ & 1 & - & - \\
Yes & 6.747 & $0.696-65.376$ & 0.0994 \\
ER & & & - \\
Negative & 1 & - & $<0.0001$ \\
Positive & 0.023 & $0.005-0.102$ & - \\
ECOG & & - & 0.0038 \\
0 & 1 & $1.679-14.743$ & 0.0061 \\
1 & 4.976 & $1.860-41.466$ & \\
2 & 8.782 & & \\
\hline
\end{tabular}

ER: Estrogen receptor, ECOG: Eastern Cooperative Oncology Group.

radioembolization for the treatment of unresectable HCC (25, 26). As far as we are aware, no comparative study of the efficacy of TACE versus TARE for patients with hepatic metastases from breast cancer has been published to date. Our study did not find any statistically significant difference in OS between the TACE- and TARE-treated groups; however, there was a consistent trend towards better mRECIST response and survival favoring the TARE-treated group. Allgrade adverse events were significantly more common in patients undergoing TACE compared to TARE, which is noteworthy and may influence treatment selection in this patient population. Despite the disparity in all-grade adverse events between the two groups, the difference in high-grade adverse events did not reach statistical significance. We must point out that only patients in the TACE group experienced high-grade events, which may again suggest that TARE is a safer therapeutic modality. Of note, our rate of high-grade events $(9 \%)$ was lower than reported in the recent study by Lin et al. (7). We reason that smaller bead size may result in improved efficacy at the expense of greater toxicity $(27,28)$.

This study has many limitations. Firstly, it was limited by the inherent retrospective design along with the small sample size of both groups, which limited the power of the study to detect differences in survival outcomes. Secondly, there was no consistency in the treatment protocol (both glass and resin ytrrium-90 beads were used, the delivered doxorubicin dose varied, etc.), which may potentially have influenced the results. Thirdly, the time to follow-up imaging was different between the two groups, which may cause lead time bias. Fourthly, the use of two different imaging modalities to assess treatment response was due to our change in practice from CT to MRI. Unfortunately, this may affect interpretation of mRECIST response. Lastly, there was inherent selection bias in the selection of patients for each treatment modality despite the fact that both groups had similar background variables. 


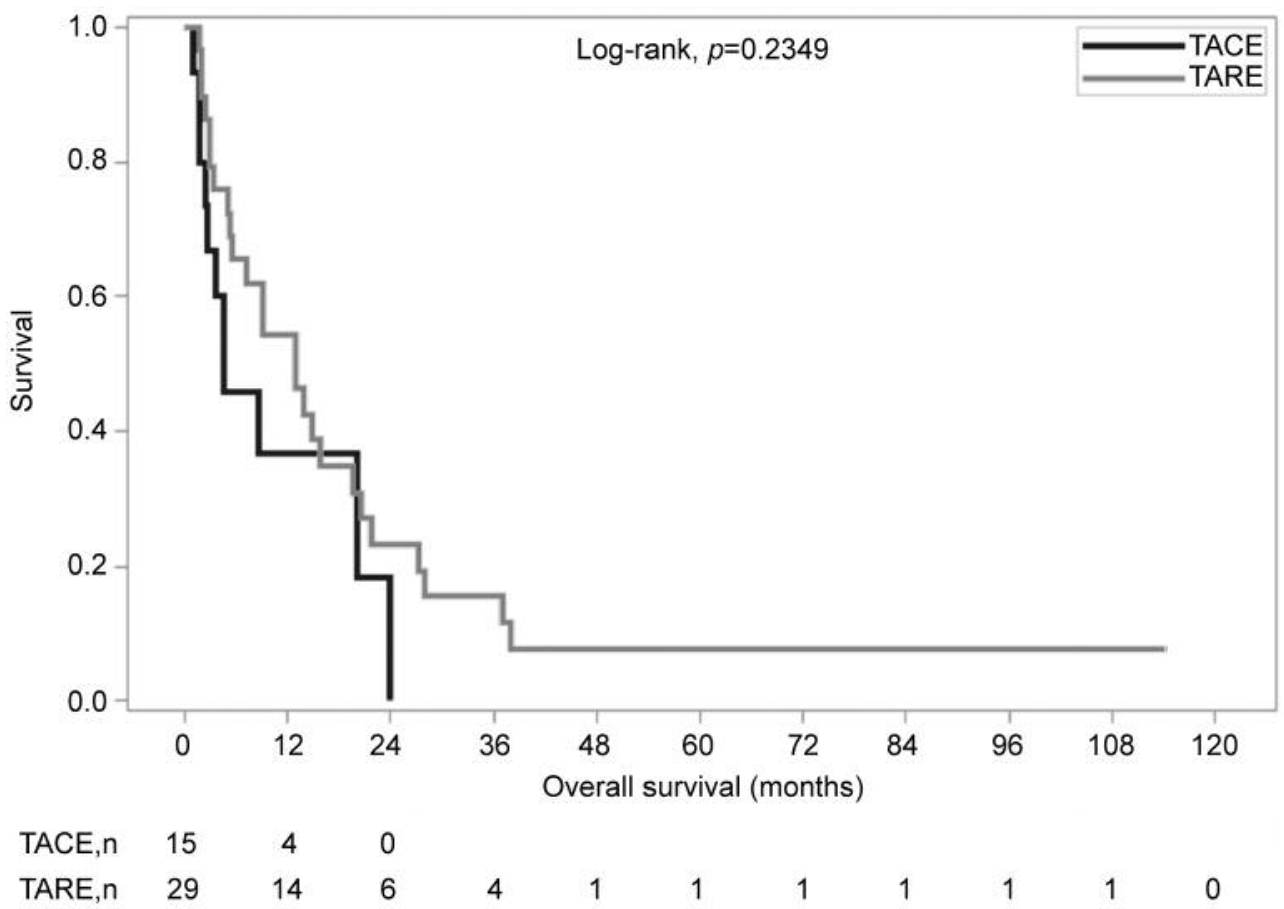

Figure 1. Kaplan-Meier curves demonstrate no significant difference in overall survival between transarterial chemoembolization (TACE) and transarterial radioembolization (TARE) groups.

Table VI. Summary of the literature on $90 Y$ radioembolization.

\begin{tabular}{|c|c|c|c|c|}
\hline Study, year & $\begin{array}{c}\text { Number of } \\
\text { patients }\end{array}$ & Study details & $\begin{array}{l}\text { Prior treatment } \\
\text { failure }\end{array}$ & $\begin{array}{l}\text { Median survival } \\
\text { (months) }\end{array}$ \\
\hline Present study, 2017 & 30 & SIR-Spheres $(94 \%)$, TheraSpheres $(6 \%)$ & Refractory & 12.9 \\
\hline Gordon et al. (8), 2014 & 75 & ThereSpheres & Refractory & 6.6 \\
\hline Saxena et al. (9), 2014 & 40 & SIR-Spheres & Refractory & 13.6 \\
\hline Pieper et al. (10), 2016 & 44 & SIR-Spheres $(93 \%)$, TheraSpheres $(7 \%)$ & Refractory & 6.6 \\
\hline Fendler et al. (11), 2016 & 81 & SIR-Spheres & Refractory & 8.8 \\
\hline Haug et al. (20), 2012 & 58 & SIR-Spheres & Refractory & 11.8 \\
\hline Cianni et al. (21), 2013 & 52 & SIR-Spheres & Refractory & 11.5 \\
\hline
\end{tabular}

Table VII. Summary of the literature on transarterial chemoembolization (TACE).

\begin{tabular}{|c|c|c|c|c|}
\hline Study, year & $\begin{array}{l}\text { Number of } \\
\text { patients }\end{array}$ & Study details & $\begin{array}{l}\text { Prior treatment } \\
\text { failure }\end{array}$ & $\begin{array}{l}\text { Median survival } \\
\text { (months) }\end{array}$ \\
\hline Present study, 2017 & 17 & $\begin{array}{c}\text { Conventional TACE with doxorubicin (3\%), } \\
\text { doxorubicin-eluting beads }(97 \%)\end{array}$ & Refractory & 4.6 \\
\hline Lin et al. (7), 2017 & 23 & Doxorubicin-eluting beads & Refractory & 17 \\
\hline Giroux et al. (22), 2004 & 8 & $\begin{array}{l}\text { Cisplatin, doxorubicin, mitomycin, ethiodized } \\
\text { oil mixed with polyvinyl alcohol particles }\end{array}$ & Refractory & $($ Mean=6) \\
\hline Eichler et al. (23), 2013 & 43 & $\begin{array}{l}\text { Gemcitabine, Lipiodol, degradable starch } \\
\text { microsphere (Embocept) suspension }\end{array}$ & Unresectable & 10.2 \\
\hline Martin et al. (24), 2012 & 40 & Doxorubicin-eluting beads & Unresectable & 47 \\
\hline
\end{tabular}


In conclusion, TARE was found to be better tolerated than TACE for the treatment of hepatic oligometastatic breast cancer. There was a trend towards better mRECIST survival favoring TARE; however, this was not found to be statistically significant. Larger studies are needed to validate these findings.

\section{References}

1 Jemal A, Ward EM, Johnson CJ, Cronin KA, Ma J, Reyerson B, Mariotto A, Lake AJ, Wilson R, Sherman RL, Anderson RN, Henley SJ, Kohler BA, Penberthy L, Feuer EJ, and Weir HK: Annual Report to the Nation on the Status of Cancer 1975-2014, featuring survival. J Natl Cancer Inst 109(9): 1-22, 2017.

2 Siegel R, Naishadham D and Jemal A: Cancer Statistics 2013. CA Cancer J Clin 63(1): 11-30, 2013.

3 O'Shaughnessy J: Extending survival with chemotherapy in metastatic breast cancer. Oncologist 10(Suppl 3): 20-29, 2005.

4 Cumings MC, Simpson PT, Reid LE, Jayanthan J, Skerman J, Song S, McCart Reed AE, Kutasovic JR, Morey AL, Marquart L, O'Rourke P and Lakhani SR: Metastatic progression of breast cancer: Insights from 50 years of autopsies. J Pathol 232(1): 2331, 2014.

5 Zinser JW, Hortobagyi GN, Buzdar AU, Smith TL and Fraschini G: Clinical course of breast cancer patients with liver metastases. J Clin Oncol 5: 773-782, 1987.

6 Chua TC, Saxena A, Liauw W, Chu F and Morris DL: Hepatic resection for metastatic breast cancer: A systematic review. Eur J Cancer 47(15): 2282-2290, 2011.

7 Lin Y, Medioni J, Amouyal G, Dean C, Sapoval M and Pellerin O: Doxorubicin-Loaded 70-150 $\mu \mathrm{m}$ microspheres for liverdominant metastatic breast cancer: Results and outomes of a pilot study. Cardiovasc Intervent Radiol 40: 81-89, 2017.

8 Gordon AC, Gradishar WJ, Kaklamani VG, Thuluvath AJ, Ryu RK, Sato KT, Gates VL, Salem R and Lewandowski RJ: Yttrium-90 radioembolization stops progression of targeted breast cancer liver metastases after failed chemotherapy. J Vasc Interv Radiol 25: 1523-1532, 2014.

9 Saxena A, Kapoor J, Meteling B, Morris DL and Bester L: Yttrium-90 radioembolization for unresectable, chemoresistant breast cancer liver metastases: A large single-center experience of 40 patients. Ann Surg Oncol 21: 1296-1303, 2014.

10 Pieper CC, Meyer C, Wilhelm KE, Block W, Nadal J, Ahmadzadehfar H, Willinek WA and Schild HH: Yttrium-90 radioembolization of advanced, unresectable breast cancer liver metastases - a single-center experience. J Vasc Interv Radiol 27: 1305-1315, 2016.

11 Fendler WP, Lechner H, Todica A, Paprottka KJ, Jakobs TF, Michl M, Bartenstein P, Lehner S and Haug AR: Safety, efficacy, and prognostic factors after radioembolization of hepatic metastases from breast cancer: A large single-center experience in 81 patients. J Nucl Med 57: 517-523, 2016.

12 Cremonesi M, Chiesa C, Strigari L, Ferrari M, Botta F, Guerriero F, De Cicco C, Bonomo G, Orsi F, Bodei L, Dia AD, Grana, CM and Orecchial R: Radioembolization of hepatic lesions from a radiobiology and dosimetric perspective. Front Oncol 4: 210, 2014. doi: 10.3389/fonc.2014.00210 [Epub ahead of print]

13 Cancer Therapy Evaluation Program, Common Terminology Criteria for Adverse Events, Version 3.0, DCTD, NCI, NIH, DHHS March 31, 2003. (http://ctep.cancer.gov), Publication Date: August 9, 2006.
14 van Persijn van Meerten EL, Gelderblom H and Bloem JL: RECIST Revised: Implications for the radiologist. A review article on the Modified RECIST Guideline. Eur Radiol 20(6): 1456-1467, 2010.

15 Sledge GW, Mamounas EP, Hortobagyi GN, Burstein HJ, Goodwin PJ and Wolff AC: Past, present, and future challenges in breast cancer treatment. J Clin Oncol 32(19): 1979-1986, 2014.

16 Kennecke H, Yerushalmi R, Woods R, Cheang MC, Voduc D, Speers CH, Nielsen TO and Gelmon K: Metastatic behavior of breast cancer subtypes. J Clin Oncol 28(20): 3271-3277, 2010.

17 Eklund JW, Trifilio S and Mulcahy MF: Chemotherapy dosing in the setting of liver dysfunction. Oncology 19: 1057-1069, 2005.

18 Field KM, Dow C and Michael M: Part I: Liver function in oncology biochemistry and beyond. Lancet Oncol 9: 1092-1101, 2008.

19 Field KM and Michael M: Part II: Liver function in oncology: Towards safer chemotherapy use. Lancet Oncol 9: 1181-1190, 2008.

20 Haug AR, Tiega Donfack BP, Trumm C, Zech CJ, Michl M, Laubender RP, Uebleis C, Bartenstein P, Heinemann V and Hacker M: ${ }^{18} \mathrm{~F}-\mathrm{FDG}$ PET/CT predicts survival after radioembolization of hepatic metastases from breast cancer. J Nucl Med 53(3): 371-377, 2012.

21 Cianni R, Pelle G, Notarianni E, Saltarelli A, Rabuffi P, Bagni O, Filippi L and Cortesi E: Radioembolisation with (90)Ylabelled resin microspheres in the treatment of liver metastasis from breast cancer. Eur Radiol 23(1): 182-189, 2013.

22 Giroux MF, Baum RA and Soulen MC: Chemoembolization of liver metastasis from breast carcinoma. J Vasc Interv Radiol 15(3): 289-291, 2004.

23 Martin RC, Robbins K, Fages JF, Romero FD, Rustein L, Tomalty D and Monaco R: Optimal outcomes for liver-dominant metastatic breast cancer with transarterial chemoembolization with drug-eluting beads loaded with doxorubicin. Breast Cancer Res Treat 132(2): 753763, 2012.

24 Eichler K, Jakobi S, Gruber-Rouh T and Hammerstingl R, Vogl TJ and Zangos S: Transarterial chemoembolization (TACE) with gemcitabine: phase II study in patients with liver metastases of breast cancer. Eur J Radiol 82(12): e816-822, 2013.

25 Akinwande $\mathrm{O}$, Philips $\mathrm{P}$, Scoggins $\mathrm{C}$ and Martin RC: Radioembolization versus chemoembolization (DEBDOX) for the treatment of unresectable hepatocellular carcinoma: A propensity-matched study. Anticancer Res 36(1): 239-246, 2016.

26 Rathmann N, Sadick M, Rathmann B, Kostrzewa M, Weiss C, Schoenberg SO, Diehl SJ and Antoni C: Benefit of patients with an early and progressed state of hepatocellular carcinoma treated with drug-eluting beads. In Vivo 30: 707-712, 2016.

27 Dreher MR, Sharma KV, Woods DL, Reddy G, Tang Y, Pritchard WF, Chiesa OA, Karanian JW, Esparza JA, Donahue D, Levy EB, Willis SJ, Lewis AL and Wood BJ: Radiopaque drug-eluting beads for transcatheter embolotherapy: experimental study of drug penetration and coverage in swine. J Vasc Interv Radiol 23(2): 257-264, 2012.

28 Lee KH, Liapi E, Vossen JA, Buiks M, Ventura VP, Georgiades C, Hong K, Kamel I, Torbenson MS and Geschwind JF: Distribution of iron oxide-containing embosphere particles after transcatheter arterial embolization in an animal model of liver cancer: Evaluation with MR imaging and implication for therapy. J Vasc Interv Radiol 19(10): 1490-1496, 2008.

Received February 27, 2018 Revised April 8, 2018 Accepted April 12, 2018 